\title{
Genitourinary fistulas experience in a tertiary hospital in North-Western Nigeria
}

\author{
Mairo Hassan', Kehinde Joseph Awosan² \\ ${ }^{1}$ Senior Lecturer, Department of Obstetrics and Gynecology, Usmanu Danfodiyo University, Sokoto, Nigeria, ${ }^{2}$ Senior \\ Lecturer, Department of Community Health, Usmanu Danfodiyo University, Sokoto, Nigeria
}

Background: Genitourinary fistulas are devastating, with obstetric fistula being the most common type and a major public health problem in the developing world. Aims and Objectives: This study was designed with an aim to determine the epidemiology of genitourinary fistulas in our centre. Materials and Methods: A 5 year ( $1^{\text {st }}$ January 2013 to $31^{\text {st }}$ December 2017) retrospective review based on data extracted from the case files of patients managed for gynecological fistulas at the Usmanu Danfodiyo University Teaching Hospital (UDUTH), Sokoto, North-Western Nigeria, was conducted. A proforma was used to extract data on the research variables. Data were analyzed using IBM SPSS version 24 computer statistical software package. Results: A total of 52 patients with genitourinary fistulas were managed in the period under review. The mean age of the patients was 28.25 \pm 10.0 years, and majority of them $(65.4 \%)$ were aged less than 30 years. Most of them $(94.2 \%)$ had no formal education, and were full-time housewives (98.1\%). Majority of the fistulas $(69.2 \%)$ were due to prolonged obstructed labor, and close to a quarter of fistulas $(23.1 \%)$ were of iatrogenic origin. About a third of patients $(32.7 \%)$ have had at least a previous fistula repair. Most of them (92.3\%) had surgical repair done, and it was successful in $65.4 \%$ of cases. Conclusion: Although, the genitourinary fistulas in this study were majorly of obstetric origin, a relatively high proportion of cases were of iatrogenic origin. Government should provide universal access to timely and appropriate obstetric care, and also empower women.

\section{Access this article online}

Website:

http://nepjol.info/index.php/AJMS

DOI: 10.3126/ajms.v9i6.21059

E-ISSN: 2091-0576

P-ISSN: 2467-9100

Key words: Genitourinary fistulas; Obstetric; latrogenic; Patients

\section{INTRODUCTION}

Genitourinary fistulas are devastating, with obstetric fistula being the most common type and a major public health problem in the developing world. ${ }^{1-5}$ Whereas, obstetric fistula was eradicated in the resource-rich countries almost a century ago, it is still prevalent in the resource-poor countries of south-Asia and sub-Saharan Africa which account for the larger proportion of the estimated 50,000 to 100,000 new cases occurring each year, with more than 2 million young women living with untreated obstetric fistula in these regions. ${ }^{2-4}$ In essence, women with obstetric fistula are indicators of the failure of the poorly-resourced health systems in the countries in these regions to deliver accessible, timely and appropriate intrapartum care to them. ${ }^{4}$
Reports from studies showed a disproportionately high burden of genitourinary fistulas in sub-Saharan Africa with far-reaching consequences on women's wellbeing, social and marital relationships, mental health and economic capacity. ${ }^{6,7}$ In addition to obstetric fistula (which is mainly caused by prolonged obstructed labor and delay in care), the other common causes of genitourinary fistulas that were reported in several studies include iatrogenic injury sustained during the course of delivery (such as at the time of laparotomy, cesarean section, or through instrumental vaginal delivery), accidents, sexual abuse and rape, and other harmful traditional practices. ${ }^{1,8-10}$

A cause for concern is the high prevalence of genitourinary fistula of iatrogenic origin reported in studies conducted in countries with very high burden of the problem 
in sub-Saharan Africa including Tanzania, ${ }^{9}$ Uganda,${ }^{10}$ Nigeria, ${ }^{11}$ and Cameroon, ${ }^{12}$ as this could worsen the situation, considering the shortage of trained surgeon and facilities for fistula repair, the very low proportion of cases that are operated yearly, and the huge backlog of patents awaiting fistula repair across the continent.

Obstetric fistula is a serious public health problem in Nigeria (particularly in the rural areas) as a result of the prevalent problem of access to quality obstetric care due to ignorance, lack of finance, logistic problems, decrepit infrastructure, cultural preferences and late decision to seek care, with an estimated 400,000-800,000 women living with the problem, and 20,000 new cases occurring every year. ${ }^{1}$

The worrisome aspect is the fact that only about 5,000 of the 20,000 new cases that occur each year in Nigeria are treated at different levels of expertise, and it is believed that at this rate, it will take about 100 years to deal with only the backlog, ignoring new cases. ${ }^{1}$ Most of the fistula repairs in Nigeria are done by specially trained fistula surgeons in the designated fistula hospitals (currently 16 in number) in the country, and treatment is provided free by the government, ${ }^{1}$ while only a few fistula repairs are done in the teaching hospitals in the country because majority of the women affected are poor, and do not have the money to access treatment at these hospitals.

In the absence of solid population-based estimates of the numbers of obstetric fistula worldwide, Stanton et al, ${ }^{13}$ had recommended the use of the sisterhood method for estimating maternal mortality in estimating the prevalence of obstetric fistula, given the ostracization associated with the condition in many places, thus making women with the problem less willing to self-report. This is further supported by the fact that for every woman who dies of pregnancy-related causes, about 20 to 30 others are left with serious morbidity (such as obstetric fistula). ${ }^{14}$

Although, the accurate number of cases of obstetric fistula in North-Western Nigeria (the study area) is unknown, the zone is believed to account for a substantial proportion of the cases in the country in view of the high maternal deaths and other associated factors in the zone. A United Nations Children's Fund (UNICEF) report showed that the NorthWest geopolitical zone had the highest proportion of women aged 15-19 years who have begun childbearing $(40 \%)$ as compared to the South-East $(6 \%)$ and SouthWest $(7 \%)$ zones. ${ }^{15}$ Also, the States in the North-West zone had the least proportion of women that were delivered by skilled attendant particularly Sokoto (7\%), Kebbi (8\%), Katsina (9\%) and Zamfara (10\%). ${ }^{15}$ Another UNICEF report also showed that the North-West zone had the second highest maternal deaths (1026 per 100,000 live births) in the country, after the North-East zone (1549 per 100,000 live births), as compared to the South-East (286 per 100,000 live births) and South-West (165 per 100,000 live births) zones. ${ }^{16}$

Despite the high burden of obstetric fistula in our locality, little is known of its pattern and peculiarities. This 5-year retrospective review was conducted to determine the epidemiology of genitourinary fistulas in our centre. The findings of the study would be invaluable in identifying the causes, and in designing appropriate strategies and interventions for the prevention and control of genitourinary fistulas in our locality.

\section{MATERIALS AND METHODS}

\section{Study design, data collection and analysis}

This was a 5year $\left(1^{\text {st }}\right.$ January 2013 to $31^{\text {st }}$ December 2017) retrospective review based on data extracted from the case files of patients managed for gynecological fistulas at the Usmanu Danfodiyo University Teaching Hospital (UDUTH), Sokoto, North-Western Nigeria. The hospital is a referral centre that serves Sokoto State and the neighboring Kebbi and Zamfara States, as well as the neighboring Niger Republic. A proforma was used to extract data on the patients' socio-demographic characteristics, causes of fistula, types of fistula, treatment given and outcome. Data were analyzed using IBM SPSS version 24 computer statistical software package. Quantitative variables were summarized using mean and standard deviation, while categorical variables were summarized using frequencies and percentages; and the results were presented as frequency distribution tables.

\section{Ethical consideration}

Institutional ethical clearance was obtained from the Ethical Committee of Usmanu Danfodiyo University Teaching Hospital, Sokoto, Nigeria. Permission to conduct the study was also obtained from the Management of the hospital.

\section{RESULTS}

A total of 52 patients with genitourinary fistulas were managed in the period under review. The ages of the patients ranged from 11 to 55 years (Mean $=28.25 \pm 10.0)$, and majority of them $(34,65.4 \%)$ were aged less than 30 years. Almost all the patients $(49,94.2 \%)$ had no formal education; and apart from the child among them, all the patients were married, and were full-time housewives. Majority of the patients (44, 84.6\%) were multi- and grandmultiparous (Table 1). 
Types of fistulas diagnosed among the patients and their causes

The most commonly diagnosed types of fistulas among the patients were mid-vaginal (36.5\%), juxta-urethral (23.1\%) and juxta-cervical (15.4\%), while vesico-uterine fistula was the least in occurrence $(1.9 \%)$. Majority of the fistulas $(69.2 \%)$ were caused by prolonged obstructed labor, and close to a quarter of fistulas $(23.1 \%)$ were of iatrogenic origin; of these, the most common causes were cesarean section $(9.5 \%)$, ruptured uterus $(5.8 \%)$ and abdominal hysterectomy (5.8\%) as shown in Table 2.

Patients' past surgical history, and treatment profile and outcome

About a third, $17(32.7 \%)$ of the 52 patients have had at least a previous fistula repair; of these, the majority (52.9\%) have had two or more previous fistula repairs. Most, $48(92.3 \%)$ of the 52 patients had surgical repair (most commonly through vaginal and abdominal approaches), while $2(3.8 \%)$ were not operated. Repair was successful in majority of patients and were continent at discharge (34, 65.4\%), $5(9.6 \%)$ had failed repair, $3(5.8 \%)$ had post repair stress incontinence, and $10(19.2 \%)$ were lost to follow up (Table 3).

\section{DISCUSSION}

Despite the high burden of genitourinary fistulas in the study area (North-West Nigeria), only 52 patients were managed over a 5 -year period. This is quite low and may not contribute significantly in clearing the backlog of patients living with fistula in the area. Similar to the finding

\begin{tabular}{lc}
$\begin{array}{l}\text { Table 1: Socio-demographic characteristics of } \\
\text { patients }\end{array}$ & \\
\hline Variables & Frequency $(\%) \mathbf{n = 5 2}$ \\
\hline Age group (years) & \\
$<20$ & $9(17.3)$ \\
$20-24$ & $11(21.2)$ \\
$25-29$ & $14(26.9)$ \\
$30-34$ & $6(11.5)$ \\
$\geq 35$ & $12(23.1)$ \\
Religion & \\
Islam & $52(100)$ \\
Level of education & \\
No formal education & $49(94.2)$ \\
Primary & $3(5.8)$ \\
Marital status & \\
Married & $51(98.1)$ \\
Single & $1(1.9)$ \\
Occupation & \\
Full-time housewives & $51(98.1)$ \\
None (still a child) & $1(1.9)$ \\
Parity & \\
Primipara & $8(15.4)$ \\
Multipara & $27(51.9)$ \\
Grand multipara & $17(32.7)$ \\
\hline
\end{tabular}

in this study, only a few patients were also treated at the teaching hospitals across Nigeria, including University of Port Harcourt Teaching Hospital, Port Harcourt, Nigeria, ${ }^{17}$ where only 67 patients were managed for genital tract fistula over a 10-year period; Obafemi Awolowo University Teaching Hospital, Ile-Ife, Nigeria, ${ }^{18}$ where only 55 patients were managed over a 10-year period; and University of Ilorin Teaching Hospital, Ilorin, Nigeria ${ }^{19}$ where only 34 patients were managed over a 10 -year period. The low patient turnout for management of fistula in this study and in studies conducted in the other teaching hospitals in Nigeria could be due to the high cost of admission and surgery in the tertiary hospitals in the country, thus making their services financially inaccessible to the fistula patients who are mostly poor.

On the contrary, studies conducted in designated fistula hospitals (where treatment is offered to patients free of charge) in the neighboring Kano and Katsina States reported large turnout of patients (despite the fact that there were fewer numbers of trained fistula surgeons in these fistula hospitals as compared to the teaching hospitals). ${ }^{11,20}$ While 288 of 343 patients that presented with genital tract fistula (within a year) at the Laure Fistula Center, Murtala Mohammed Specialist Hospital, Kano, Nigeria, were operated successfully, ${ }^{20} 728$ genitourinary surgeries were carried out at the National Obstetric Fistula Centre, Babbar-Ruga, Katsina, Nigeria, within a 2 -year period. ${ }^{11}$ It is therefore evident that the snail-pace at which the backlog of patients awaiting fistula treatment is cleared in Nigeria is principally due to financial inaccessibility, and it underscores the need for the Federal Government of Nigeria to establish a designated fistula centre in all the 36 States of the Federation, including the Federal Capital Territory, instead of the paltry 16 designated fistula centres that are currently available in the country.

\begin{tabular}{lc} 
Table 2: Types of fistulas diagnosed among the \\
patients and their causes \\
\hline Variables & Frequency (\%) $\mathbf{n = 5 2}$ \\
\hline Types of fistulas diagnosed & \\
Mid-vaginal & $19(36.5)$ \\
Juxta-urethral & $12(23.1)$ \\
Juxta-cervical & $8(15.4)$ \\
Uretero-vaginal & $6(11.5)$ \\
Cervico-vaginal & $4(7.7)$ \\
Vault & $2(3.9)$ \\
Vesico-uterine & $1(1.9)$ \\
Causes of fistulas & \\
Prolonged obstructed labor & $36(69.2)$ \\
Cesarean section & $5(9.6)$ \\
Ruptured uterus & $3(5.8)$ \\
Abdominal hysterectomy & $3(5.8)$ \\
Vaginal hysterectomy & $1(1.9)$ \\
Trauma & $1(1.9)$ \\
Pelvic surgery & $1(1.9)$ \\
Post measles & $1(1.9)$ \\
Female genital mutilation & $1(1.9)$ \\
\hline
\end{tabular}




\begin{tabular}{lc} 
Table 3: Patients' past surgical history, and \\
treatment profile and outcome \\
\hline Variables & Frequency (\%) \\
\hline Have had previous surgical repair(s) & \\
$(\mathrm{n}=52)$ & \\
Yes & $17(32.7)$ \\
No & $35(67.3)$ \\
Number of previous repair (s) & \\
(n=17) & \\
Once & $8(47.1)$ \\
Twice & $7(41.2)$ \\
Four times & $2(11.7)$ \\
Treatment profile ( $\mathrm{n}=52)$ & \\
Surgical repair: & \\
Vaginal approach & $26(50.0)$ \\
Abdominal approach & $17(32.7)$ \\
Combined vaginal and abdominal & $5(9.6)$ \\
Catheter & $2(3.8)$ \\
Not operated & $2(3.8)$ \\
Outcome of treatment ( $\mathrm{n}=52)$ & \\
Continent & $34(65.4)$ \\
Failed repair & $5(9.6)$ \\
Post repair stress incontinence & $3(5.8)$ \\
Lost to follow up & $10(19.2)$ \\
\hline
\end{tabular}

The relatively young age of the patients in this study with a mean age of $28.25 \pm 10.0$ years, close to a fifth of them $(17.3 \%)$ being aged less than 20 years, and majority of them $(65.4 \%)$ being aged less than 30 years, reflects the cultural practice of early marriage for the girl child in Northern Nigeria; their education is disrupted, they become pregnant early in life when their pelvis is not fully mature, lack access to appropriate obstetric care and inevitably develop obstetric fistula together with its dire consequences. It is therefore not surprising that almost all the patients in this study had no formal education (94.2\%), and were full-time house-wives $(98.1 \%)$. Studies conducted in other hospitals in Nigeria, ${ }^{11,17,19,20}$ and other sub-Saharan African countries including Zambia, ${ }^{21}$ Ethiopia, ${ }^{22}$ and Uganda, ${ }^{23}$ majorly reported similarly young population of obstetric fistula patients, with little or no formal education and unemployed. A meta-analysis of national household surveys that included data for 262,100 women of reproductive age (15-49 years) in 19 sub-Saharan African countries reported a very high prevalence of symptoms of vaginal fistula, with a lifetime prevalence of 3.0 cases $(95 \%$ Confidence Interval [CI]: 1.3-5.5) per 1000 women. ${ }^{6}$ In essence, obstetric fistula has become the "symbol of poverty" among women in sub-Saharan Africa, and this suggests the need for the governments of the respective countries to adopt a holistic approach that encompasses provision of universally accessible, timely and appropriate obstetric care, as well as women empowerment (through female education, female employment and female emancipation) in tackling the high burden of genitourinary fistulas across the continent. It is believed that women empowerment facilitates appropriate health seeking behavior, particularly utilization of healthcare services by enabling them to overcome physical, financial and intellectual barriers to accessing the services.

The finding of majority $(69.2 \%)$ of the genitourinary fistulas in this study being of obstetric origin is in consonance with the finding in studies conducted in Nigeria $^{17-19}$ and other sub-Saharan African countries ${ }^{12,21,22}$ and it exposes the failure of the health systems in the countries across the continent to deliver accessible, timely and appropriate intrapartum care to pregnant women.

The finding of close to a quarter $(23.1 \%)$ of the genitourinary fistulas in this study being of iatrogenic origin (particularly cesarean section, abdominal hysterectomy and surgery for ruptured uterus) is disturbing considering the similarly high prevalence $(16.1 \%)$ of iatrogenic genitourinary fistula obtained in a study conducted in the neighboring Katsina State, Nigeria, ${ }^{11}$ and the procedures that lead to the development of the fistulas were reported to have been conducted at the secondary healthcare centers in most $(87.5 \%)$ of the cases. Similarly, high iatrogenic fistula prevalence rates were reported in studies conducted in other sub-Saharan African countries including Uganda $(25 \%),{ }^{10}$ and Cameroon (19.78\%). ${ }^{12}$ These findings are alarming as they imply that women in Africa face a "doubleedged sword" in the course of performing their normal reproductive function, as those who are lucky enough to escape developing obstetric fistula early in their marriage, have iatrogenic fistula to content with later in life, as the overworked and poorly supervised medical officers serving at the inadequately equipped lower levels of healthcare appear to be more preoccupied with saving their lives in the critical situations in which the women often present at the hospital. It is therefore imperative for the governments of the sub-Saharan African countries to strengthen the health systems in their respective countries and make sufficient resources (including money, materials, and manpower) available for provision of universally accessible, timely and appropriate obstetric care.

While the prevalence of successful fistula closure in this study $(65.4 \%)$ is lower than the $73.6 \%$ obtained in a study conducted at a designated fistula centre in the neighboring Katsina State, ${ }^{11}$ it is much higher than the $32 \%$ prevalence of successful fistula closure obtained in a study conducted at another teaching hospital in Ile-Ife, Nigeria. ${ }^{18}$ This could be due to the fact that a substantial proportion of the patients in this study $(32.7 \%)$ have had at least a failed fistula repair previously; and of these, more than half $(52.9 \%)$ have had 2 to 4 previous failed repairs. Fistula repair is a very delicate and complex procedure that involves operating in a confined space with distorted anatomy and rigidity of tissues, ${ }^{24}$ and 
success is best achieved at first-time surgery. It means that the more the number of failed repairs, the less the likelihood of success. This is corroborated by the finding in a study by Raasen et al, ${ }^{25}$ that reported $93.8 \%$ fistula closure rate among 639 East African women that had first-time surgery for obstetric fistula. In addition, patients that were operated on within 3 months of developing fistula had a slightly better surgical outcome $(93.9 \%)$ than those that had surgery after more than 3 months of developing fistula $(87.0 \%)$.

These findings re-emphasize the need to establish more fistula centers in the country, and also train more fistula surgeons to manage the centers, in view of the fact that fistula repair is not a core component of the doctors' training curriculum in Nigeria. The skills are usually acquired through regular "hands on work" and regular coaching by more experienced surgeons over a long period of time. ${ }^{24} \mathrm{It}$ is therefore necessary for the postgraduate training institutions to make fistula repair a core component of the curriculum of the residency training in Obstetrics and Gynecology; and the residents should be made to undergo mandatory postings in the designated fistula hospitals for a period of time that is sufficient for the required exposures and skills acquisition.

\section{CONCLUSION}

Although, the genitourinary fistulas in this study were majorly of obstetric origin, a relatively high proportion of cases were of iatrogenic origin. Government should provide universal access to timely and appropriate obstetric care, and also empower women.

\section{Limitation of the study}

This was a single centre based study; the generalizability of the findings is therefore limited.

\section{ACKNOWLEDGEMENTS}

The authors appreciate the management of Usmanu Danfodiyo University Teaching Hospital, Sokoto, Nigeria, for giving the permission to conduct the study. The head and staff of the Medical Records Department are also appreciated for their cooperation.

\section{REFERENCES}

1. Federal Ministry of Health $(\mathrm{FMoH})$, Nigeria. Standard of practice on obstetric fistula in Nigeria, Doctors' version. Abuja, Nigeria: FMoH; 2011. Available from: https://www.health.gov. ng/doc/DOCTOR'S\%20VERSION\%201.pdf. [Last accessed on 2018 September 1].

2. UNFPA. The second meeting of the working group for the prevention and treatment of obstetric fistula, Addis Ababa, 30 October-1 November, 2002. Available from: https://www. unfpa.org/publications/second-meeting-working-groupprevention-and-treatment-obstetric-fistula [Last accessed on 2018 September 1].

3. World Health Organization (WHO). 10 facts on obstetric fistula. Geneva, Switzerland: WHO; 2018. Available from: https://www. who.int/features/facilities/obstetric-fistula/en/. [Last accessed on 2018 September 1].

4. Tuncalp O, Tripathy V, Landry E, Stanton CK and Ahmed S. Measuring the incidence and prevalence of obstetric fistula: approaches, needs and recommendations. Bull WHO 2015; 93: 60-62.

5. Creanga AA and Genadry RR. Obstetric fistulas: a clinical review. Int J Gynaecol Obstet 2007; 99 Suppl 1: S40-46.

6. Maheu-Giroux M, Filippi V, Samadoulougou S, Castro MC, Maulet N, Meda N, et al. Prevalence of symptoms of vaginal fistula in 19 sub-Saharan Africa countries: a meta-analysis of national household survey data. Lancet Glob Health 2015; 3(5); e271-278. https://doi.org/10.1016/s2214-109X(14)70348-1.

7. Bashar DT, Worku AG and Mengistu MY. Consequences of obstetric fistula in sub-Saharan African countries from patients' perspective: a systematic review of qualitative studies. BMC Women's Health 2018; 18: 106. https://doi.org/10.1186/s12905018-0605-1.

8. Wall LL, Karshima JA, Kirschner $C$ and Arrowsmith SD. The obstetric vesicovaginal fistula: characteristics of 899 patients from Jos, Nigeria. Am J Obstet Gynecol 2004; 190(4):1011-1019.

9. Mteta KA, Mbwambo $\mathrm{J}$ and Mvungi $\mathrm{M}$. latrogenic ureteric and bladder injuries in obstetric and gynaecologic surgeries. East Afr Med J. 2006; 83(1): 79-83.

10. Barageine JK, Tumwesigye NM, Byamugisha JK, Almroth L and Faxelid S. Risk factors for obstetric fistula in Western Uganda; a case control study. PLoS ONE 2014; 9(11): e112299. https://doi. org/10.1371/journal.pone.0112299.

11. Nasir S, Elladan AM, Hassan M and Panti AA. Pattern and Outcome of latrogenic Genitourinary Fistula from Obstetric and Gynaecological Surgeries in a Tertiary Institution, North-Western Nigeria. AJMAH 2018; 10(3): 1-7.

12. Tebeu PM, Touka EB, Mawamba Y, Toyou C, Formulu JN and Rochat $\mathrm{CH}$. The pattern of non-obstetric fistula: a Cameroon experience. Asia Pac J Reprod 2014; 3(3): 238-240.

13. Stanton $\mathrm{C}$, Holtz $\mathrm{SA}$ and Ahmed $\mathrm{S}$. Challenges in measuring obstetric fistula. Int J Gynaecol Obstet. 2007; 99 Suppl 1:S4-9.

14. Firoz $T$, Chou D, von Dadelszen P, Agrawal P, Vanderkruk R, Tuncalp $O$, et al. Measuring maternal health: focus on maternal morbidity. Bulletin of the World Health Organization 2013; 91: 794-796.

15. United Nations Children's Fund (UNICEF). Fact Sheets, HEALTH, Nigeria. Available from: https://www.unicef.org/ nigeria/factsheets_HEALTH_low.pdf [Last accessed on 2018 September 6].

16. United Nations Children's Fund (UNICEF). Mother, newborn and child health and mortality in Nigeria - General facts. Available from: https://www.unicef.org/nigeria/ng-publications advocacybrochure.pdf [Last accessed on 2018 September 6].

17. Inimgba NM, John CO and Ekeke NO. Genitourinary Fistulas Experience in a University Teaching Hospital: A South-South Nigeria Perspective. Greener J Med Sci 2018; 8(1): 006-010.

18. Olusegun AK, Akinfolarin AC and Olabisi LM. A review of clinical pattern and outcome of vesicovaginal fistula. J Nat Med Assoc 2009; 101(6): 593-595.

19. Ijaiya MA and Aboyeji PA. Obstetric urogenital fistula: the llorin experience, Nigeria. West Afr J Med 2004; 23(1): 7-9.

20. Ahmed ZD, Abdullahi HM, Yola Al and Yakasai IA. Obstetrics fistula repairs in Kano, Northern Nigeria: the journey so far. Ann 
Trop Med Public Health 2013; 6:545-548.

21. Holme A, Breen M and MacArthur C. Obstetric fistulas: a study of women managed at the Monze Mission Hospital, Zambia. BJOG 2007; 114(8); 1010-1017.

22. Sori DA, Azale AW and Gemeda DH. Characteristics and repair outcomes of patients with vesicovaginal fistula managed in Jimma University Teaching Hospital, Ethiopia. BMC Urology 2016; 16: 41. https://doi.org/10.1186/s12894-016-0152-8.

23. McCurdie FK, Moffatt $\mathrm{J}$ and Jones K. Vesicovaginal fistula in
Uganda. J Obstet Gynaecol 2018; 38(6): 822-827.

24. Hancock B. Vesico-vaginal and rectovaginal fistula "In" von Beekhuizen $\mathrm{H}$ and Unkels R (editors). A Textbook of Gynecology for Less-Resourced Locations. 1 $^{\text {st }}$ ed.London, UK: Sapien Publishing Ltd; 2012. Pp 233-274.

25. Raasen JT, Verdaasdonk EG and Vierhout ME. Prospective results after first-time surgery for obstetric fistulas in East African women. Int Urogynecol J Pelvic Floor Dysfunct 2008; 19(1): 73-79.

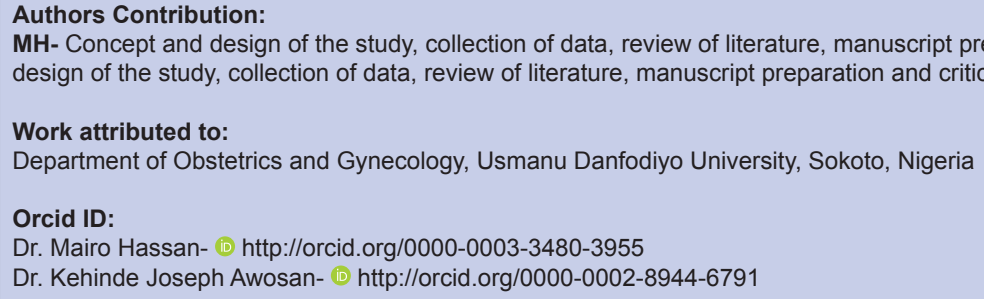

